\title{
Quantifying the axial magma lens dynamics at the roof of oceanic magma reservoirs (dike / gabbro transition): Oman Drilling Project GT3 site survey
}

\author{
LYDÉRIC FRANCE ${ }^{1}$, MAEVA LOMBARD ${ }^{2}$, CHRISTIAN \\ NICOLLET $^{3}$, CAROLE BERTHOD ${ }^{4}$, BAPTISTE DEBRET ${ }^{5}$, \\ JUERGEN KOEPKE ${ }^{6}$, BENOIT ILDEFONSE ${ }^{7}$ AND AURORE \\ TOUSSAINT $^{1,8}$ \\ ${ }^{1}$ Université de Lorraine, CNRS, CRPG \\ ${ }^{2}$ 1. Université de Lorraine, CNRS, CRPG, F-54000 Nancy, \\ France \\ ${ }^{3}$ Université Clermont Auvergne \\ ${ }^{4}$. Laboratoire Magmas et Volcans, Université Clermont \\ Auvergne - CNRS - IRD, OPGC \\ ${ }^{5}$ Université de Paris, Institut de physique du globe de Paris \\ ${ }^{6}$ Institut fuer Mineralogie; Hannover \\ ${ }^{7}$ Université de Montpellier \\ ${ }^{8}$ Institute of Earth Sciences, University of Lausanne, 1015 \\ Lausanne, Switzerland \\ Presenting Author: lyderic.france@univ-lorraine.fr
}

At oceanic spreading centers, the interactions between the igneous system that builds the crust, and the hydrothermal system that cools it govern the plumbing system architecture and its thermokinetic evolution. At fast-spreading centers, most of those interactions occur around the axial magma lens (AML) that feeds the upper crust, and possibly part of the underlying mushy igneous reservoir. Heat extracted from crystallizing AML is transferred through a conductive boundary layer to the overlying hydrothermal system. Quantifying the AML physical and thermal evolutions and its interactions with hydrothermal system is therefore essential to understand oceanic accretion. Those general issues were the rationale of drilling ICDP OmanDP Hole GT3A, and we present herein the geological, structural, and petrological data that were used as a site survey to select its location. GT3 area enables observations in three dimensions of fossilized AMLs and overlying dikes. The new field data and corresponding mineral compositions are used together with thermokinetic and thermodynamic models to deliver an integrated dynamic model for the AML / hydrothermal system interactions. Results attest that the isotropic gabbro interval is composite, with gabbro bodies intruding and reheating both gabbros and dikes (up to $1040^{\circ} \mathrm{C}$ ). We show that AMLs should be considered as transient igneous bodies that likely crystallize from primitive MORBs in decades, releasing heat to the intruded hosts, and feeding high temperature vents on the seafloor. We show for the first time that the thermal gradient recorded in AML roof is consistent with the heat fluxes reported at active hydrothermal vents. 